\title{
Experiments Based Integral Design of Architecture and Structure
}

\author{
Linxue Li and Jinjin Wang \\ College of Architecture and Urban Planning \\ Tongji University \\ Shanghai, China \\ landwell@hotmail.com, darkangel_wjj@msn.com
}

\author{
Jie Wu \\ Architectural Design \& Research Institute \\ of Tongji University (Group) Co. Ltd. \\ Shanghai, China
}

\begin{abstract}
This paper describes an integrated design approach, which aims to interpenetrate and reconstruct the boundaries of architectural design and structural engineering. There are four relevant experiments involved in this paper. The specific design strategies varies in this four practical projects: the first two refer to the consistency of structural system and space representation; and the latter two are experiments on performances of construction materials.
\end{abstract}

Keywords-experiments; integral design; architecture; structure

\section{INTRODUCTION}

Today, in an increasingly complex environment- a claim that can evidently no long be refuted-a profession as rich in tradition as that of the architect is also looking for new "assurance" [1].

Hanif Kara, structural engineer and professor at Harvard GSD, who held his experimental design course from the perspective of a structural engineer. As an architect interested and experienced in the possibilities of structures, I found the crossover way of thinking fairly inspiring. From the experimental point of view, it is an important theoretical discourse as well as practical strategy in contemporary architecture to push back the frontier of architectural design and practice through the creatively integrated design of architects and structural engineers. To a great extent, the progress of contemporary architecture relies on the reconstruction of the knowledge system: on one hand, architects should be aware that the technological innovation of the structural system itself is the foundation of contemporary architecture design, which requires the enhancement of architects' knowledge; on the other hand, as the knowledge system involves the interpenetration and reconstruction of the boundaries of architecture and structural engineering, it is almost impossible for architects to complete the exploration of the new material, new construction method and system independently.

Looking back into the history of Modern Architecture, Le Corbusier's Domino system is the most well-known prototype for the definition of construction system and the unlimited

The paper is supported by the National Natural Science Foundation of China (Project No. 51278340). expansion of space, where there is an intention of stability behind the construction of the universal space system. However, concerning Modern Architecture, contemporary architects have a critical thinking on this Domino system. Toyo Ito tried to reconstruct a system closely related to the order and forces of nature - the natural world is extremely complicated and variable, and its system are fluid-it is built on a fluid world. In contrast to this, architecture has always to establish a more stable system [2]. Cecil Balmond who cooperated with Toyo Ito as a structural engineer made his own contribution based on his 'Informal' theory - the informal has three principal characteristics: local, hybrid and juxtaposition. They are active ingredients of an animate geometry that embrace the linear and non-linear. Both Cartesian and post Einsteinian geometry are encompassed by it [3]. Christian Kerez pursues the unlimited transparent boundary in his design. The increased level of complexity in architectural projects leads to new solutions and also creates new possibilities [1]. Meanwhile, the exploration of the new territory of architecture also relies on the collaboration of architects and structural engineers based on experiments. The collaboration between Thomas Heatherwick and Hanif Kara for the UK Pavilion at Shanghai Expo 2010 is an outstanding case of exploration of the new material and its expression. This 'Seed Cathedral' waving in the wind was built on an informal structural experiment of acrylic instead of on experience.

The practice of Atelier $\mathrm{L}+$ is also based on a new integrated system, to explore the boundary of the architectural and structural design. There are four aspects we mainly work on.

\section{MEGA-STRUCTURE: ITS CHALLENGE AND REPRESENTATION}

The project of Hangzhou Civic Center tries to explore the new type of mega-structure involving urban vertical landscape (Fig. 1). The elevated corridors with a maximum span of 75 meters which are 85 meters up in the sky constitute an important part of the mega-structure. Through experiments, architects and engineers have built up a complete system of design, production, transportation, installation, and performance optimization. 


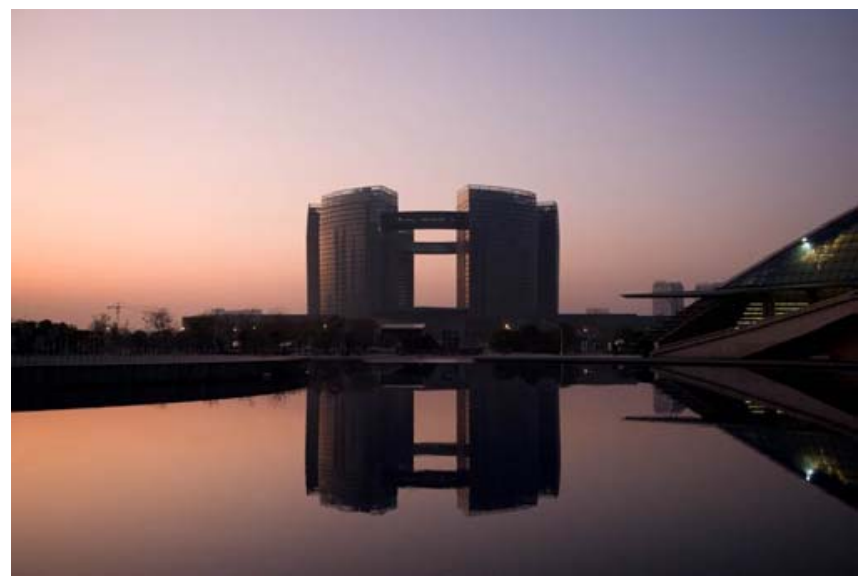

Fig. 1. The front view of Hanghzou Civic Center. (Photographer: SS)

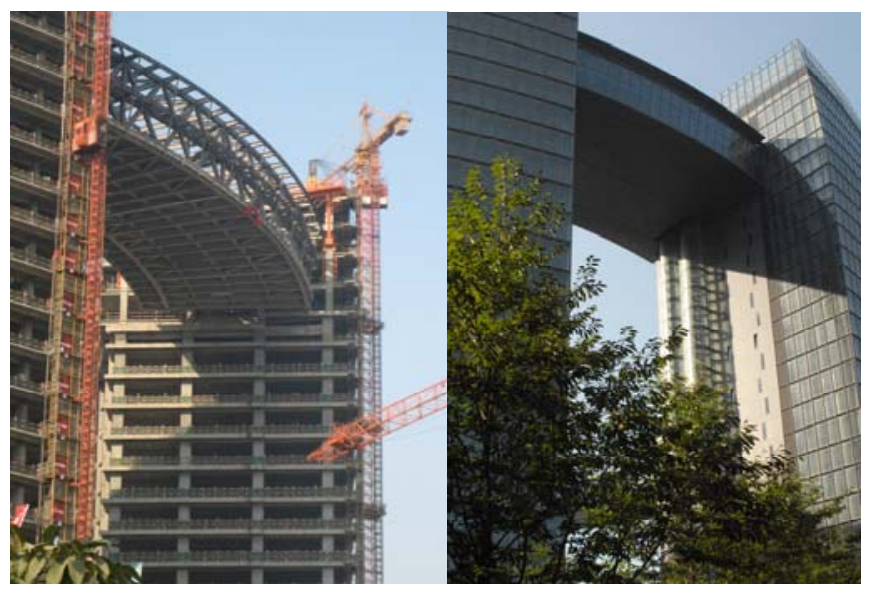

Fig. 2. The process of 'whole hydraulic lifting' of the sky-bridges (left); The complete sky-bridges (right) (Photographer: Linxue Li)

It took a long period of exploration for the formation of sky bridges, which has finally become the icon of the megastructure. The giant-scale of sky bridges (six groups of steel truss system, each 8.1 meters high and nearly 20 meters long) became one of the biggest problems in structural design. After several experiments, the structural engineer decided to use the hinged connection between sky bridges and the main buildings, which had a smaller impact on each other and was more economy. However, the structural design of the connectors brought a great challenge to the designers. It was finally worked out. One end of the bridge was hinged to the main building and the other end as effect as sliding support to the adjacent main building, thus solved the possible influence due to the displacement of the bridges.

Besides the structural design, the process of assembling, installation and construction of the sky bridges was another challenge in the whole project. The designers, construction workers, and manufacturers collaborated with each other to fulfill this extremely complicated task: first of all, a construction plan of 'whole hydraulic lifting' [5] had been made; secondly, the steel trusses were assembled from segments in the factory; after that they were transported to the site, and lifted to the specific height by four hydraulic lifters at its four corners; at last they were moved to the precise place connected with the main building. This construction experiment not only reduced the difficulty of assembling and welding high above the ground but also ensured the overall stability of the sky bridges, which contributes to the construction of future mega-structure as a successful example. (Fig. 2)

\section{RESPONDING TO THE NATURE: AN INTEGRATION OF ARCHITECTURAL AND STRUCTURAL DESIGN}

The Harbor of Yellow Estuary Ecological Tourism Zone was built on a minimum stretch of ground to minimize the damage to the natural wetland. The design concept has been realized by a combination of four core tubes and the steel suspension system, which achieved consistency for both its enclosure structure and interior spaces, meanwhile integrating the building into nature as much as possible (Fig. 4).

\section{A. Consistency of structural system and space representation}

"The intangible concept of the structure is realized through construction, and it is given visual expression through tectonics" [4]. To some extent, structural system is the most direct tool to realize the design concept. When there is high consistency between structure and its space representation, the designer's concept can be realized to its maximum extent. In this project, the architect chose to 'minimize' the adverse impacts on the wetland with a no-compromise attitude to intervene the building into nature with an open and transparent volume [6]. With a height of nearly 40 meters, four oblique concrete core tubes (flat size of about $9.3 \mathrm{~m} \times 9.8 \mathrm{~m}$ ) went through two suspended 'glass boxes', whose enclosure structure was composed of square units (diagonal length is 2.5 meters) rotated 45 degrees. Both steel suspension trusses were 2.5 meters in height and had a cantilever of almost 9 meters. After all, the structural system achieved the perfect visual effect.

\section{B. Modulus Control and Structure}

The diagonal length of each square grid unit constituted the modulus of the entire façades as well as the interior structure. The division of all the facades and the interior space was controlled within the limits of the modulus control which was 2.5 meters (including multiples of 1/2). The steel suspension trusses were 2.5 meters in height. The parapet wall on the top was 1.25 meters in height. The mezzanine on the side was 3.75 meters in height. The entire length of the complex was 115 meters, etc. The scale was highly unified with the modulus unit.

\section{Mechanic Performance of the Joints Design}

The aim of excellent structural design is a sense of balance among all the structural components. However, architects usually pay great attention to the visual qualities of their works. Therefore, it requires constant coordination and mutual adaptation between architects and structural engineers to achieve a status satisfactory to both groups. Similar situation could be found in this project. The joints of the grid structure would be more beautiful and light in visual effects using hinges. Yet it would be difficult for construction and the reliability would be far less than stiff joints. After several rounds of 
discussion, the structural engineers decided to work the joints into a combined structure. It consisted of a cylinder as the welding carrier, four slant rod pieces as major rigid connections, two transverse forms hinged by pull rods (Fig. 5). The structure was more reasonable and definite in mechanic performance.

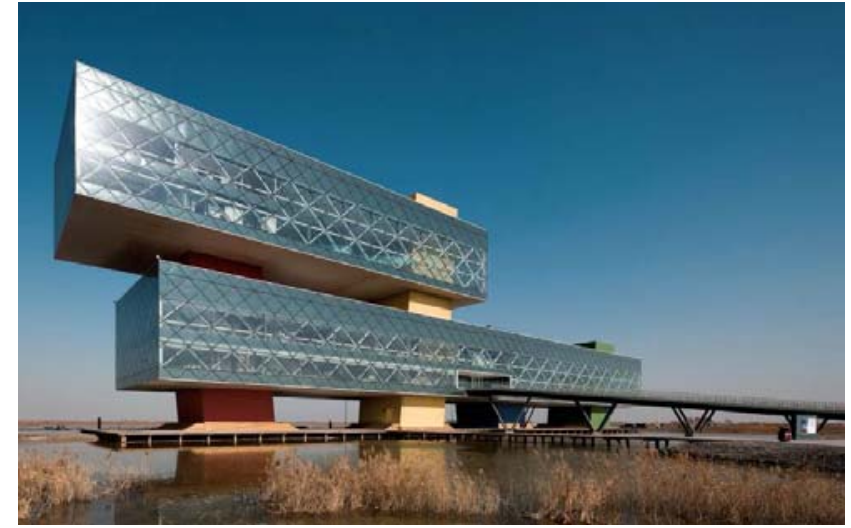

Fig. 3. The front view of the Harbor of Yellow Estuary Ecological Tourism Zone (Photographer: SS)

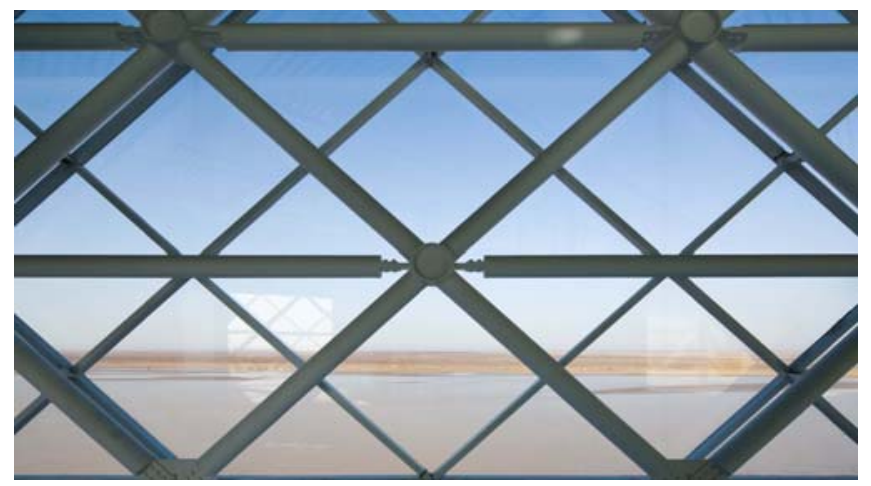

Fig. 4. The joint design of steel grid structural system (looking from the interior view) (Photographer: SS)

\section{THE EXPERIMENT OF NEW MATERIALS AND THE INNOVATION OF THE ARCHITECTURAL SYSTEM}

The design of the Tourist Service Center of Yellow Estuary Ecological Tourism Zone was based on the concept of fused with the wild landscape. The buildings constructed with rammed earth integrate into the wetland (Fig. 5). What's more, it was possible to draw on local resources and even recycle the materials. However, it was impossible to render an almost 10,000 square-meter three-story complex with traditional rammed-earth technique. It required an integrated and systematic structure mature in material proportion, strength test, standard breakthrough, sample wall experiment, templet system, construction machinery, training scheme, process organization and acceptance standard. Due to lack of related standards, innovation had to be based on the borderless cooperation of architects and structural engineers.

In this project, the architects tried to draw lessons from traditional construction technology and response to contemporary construction method and system with groundbreaking experiments on rammed earth. Compared to traditional rammed earth walls, the wall material in the experiment was improved in durability, weather fastness, pressure resistance, etc. The compression strength of the normal rammed earth wall is about 4.3MPa while that of this new-type rammed wall is $25.4 \mathrm{MPa}$. The experiment proved that the optimized rammed earth wall was much stronger than traditional rammed earth wall made with raw soil. The mechanic properties have been greatly improves. Therefore, the new wall has little limits to its height or length, which is possible to create richer façade texture combined with all kinds of windows (Fig. 6).

\section{A. Experiments on the Choice of Gravel}

Local earth is usually used in the construction of rammed walls. However, as Dong Ying is close to the estuary of the Yellow River, the sandy soil there has been washed by the water throughout the year into roundish grains with low strength, thus unsuitable for the construction of rammed earth walls. Consequently, the architects collected suitable samples in surrounding areas and finally chose the washed yellow gravel from Lin $\mathrm{Qu}$. The gravel there is relatively pure with high strength, which is an ideal material for rammed earth walls.

\section{B. Optimization of Material Proportion}

Cement was added to increase the strength of the wall. The use of water-proofing additive solved the problems of traditional rammed earth walls, such as low durability and poor weather fastness. Compared with common modern concrete material, the formula of the new wall has advantages in energy conservation and sustainability. The mechanic properties of the new rammed earth wall (25.4MPa compression strength) are close to that of C25 concrete (take compression strength for an example). However, in similar conditions, it can save about $13 \%$ cement compared to C25 concrete which greatly reduces the consumption of water and electricity.

\section{Optimization of Wall Constitution}

The method of CIC (Exterior mass, core thermal insulation, interior mass) wall was employed in the construction of the new rammed earth wall, which had an entire thickness of $500 \mathrm{~mm}$. An $80 \mathrm{~mm}$ thick layer of polyurethane was inserted between two $210 \mathrm{~mm}$ thick walls to achieve greater heatinsulation effect (The resistance of heat transfer of the wall $\left.\mathrm{R} 0=3.72 \mathrm{KM}^{2} / \mathrm{W}\right)$. Moreover, a grid of concrete reinforcing bars and the flexible connection with the main structure fulfilled the needs of anti-cracking and seismic resistance.

\section{Rich Texture of Façade}

In order to reinforce the mild and stretching visual effects of the rammed earth walls, ferrite yellow, brown and ferrite red dyes were added into the material which was rammed layer by layer (Fig. 7). The scenery wall at the entrance, for instance, interwove an entire Chinese landscape painting into the texture of the rammed earth which symbolized the artistic conception of distant mountains. Certainly, such a façade effect could not be achieved by traditional rammed earth walls. 


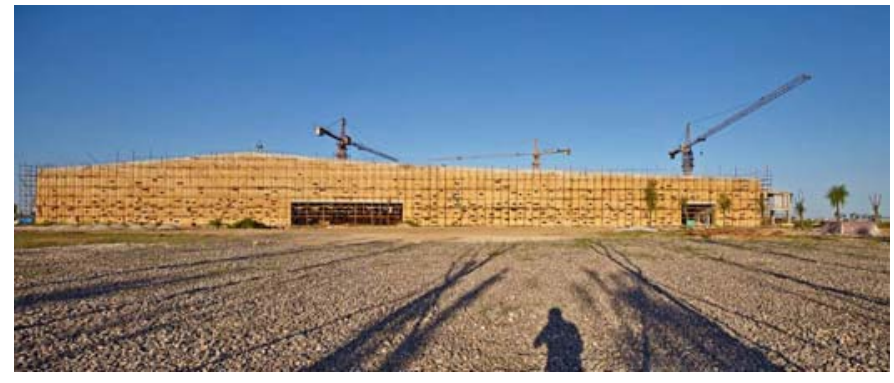

Fig. 5. Fig.5. The front view of the Tourist Service Center of Yellow Estuary Ecological Tourism Zone (Photographer: Zhang Siye)

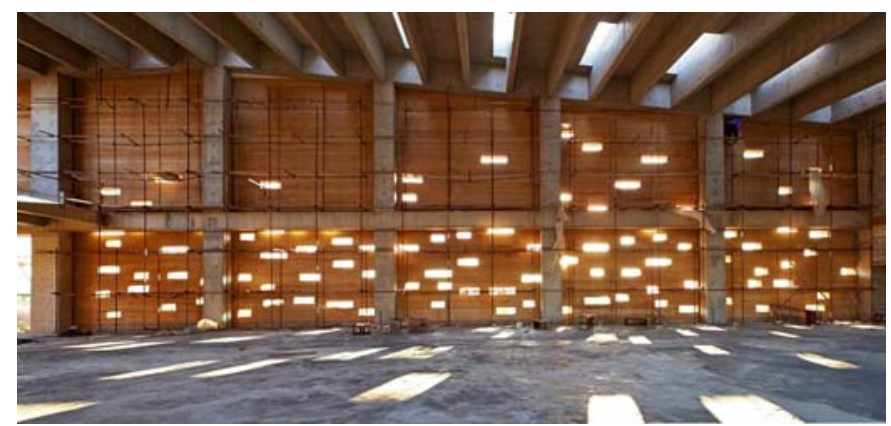

Fig. 6. The main façade with small windows (looking from the interior of the waiting hall) (Photographer: Zhang Siye)

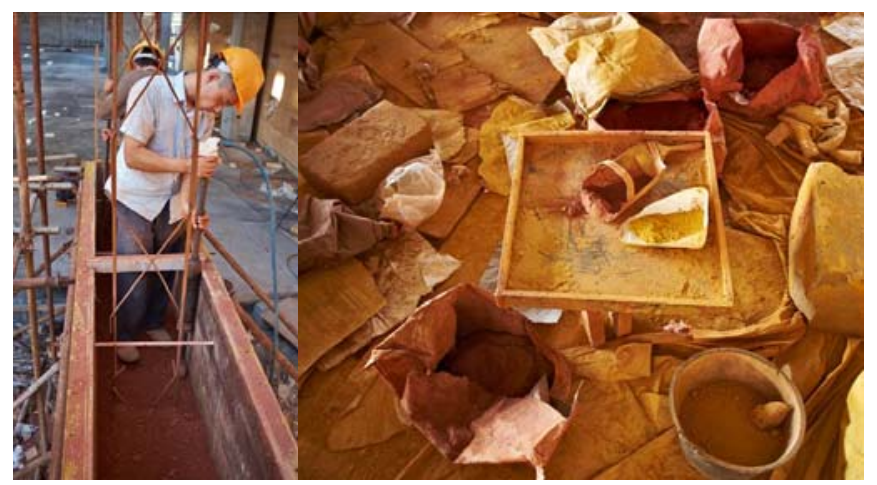

Fig. 7. The construction process of rammed earth wall (right); the natural pigments added in the rammed earth (left) (Photographer: Zhang Siye)

\section{Challenges Brought by the Extension of the BOUNDARY OF DESIGN}

The performance of acrylic in large-scale installations was involved in the project named 'Micro-Mega' (Fig. 8) of Atelier+ for 2014 SZlHK Bi-City Biennale of Urbanism and Architecture. The greatest challenge was to experiment on and integrate the teams of architects, structural engineers and manufacturers. 'Micro-Mega: Mega-scale at Urban Border' reexamined the various kinds of mega-structures constructed during the fast urbanization in China. It tried to construct a new mega-structure system with 'micro materials' as its units. The system was designed to be similar to a natural system, which could evolve, grow and conform actively to the change of environment.

During the realization of such a concept, two materials had been considered to make the 'unit modules' (84mm*60mm*45mm): aluminum and acrylic. Due to the difficulty of cutting and processing aluminum, acrylic was selected at last. The entire installation consists of more than 1400 unit modules which were joined together by bayonets (Fig. 9). The form of the installation was derived based on parameterized algorithms. There were eighty variants of the standard module bayonet which brought great challenge to the processing and construction. Although all the variants of standard modules had been numbered and sorted beforehand, it aroused big trouble in construction. The manual method of construction was time and energy consuming. Deviation in construction was inevitable. After a series of experiments, the architects and the structural engineers finally reached agreement. They decided to assemble crucial structural joints first, produce other segments in sections and at last assemble them together.

The realization of this installation proved to be a very difficult task. However, it has raised many thought-provoking questions to architects. For example, how can we combine 'high-tech' parameterization with 'low tech' construction method of contemporary China to create more interesting and diversified space? Perhaps it is the truly relevant question.

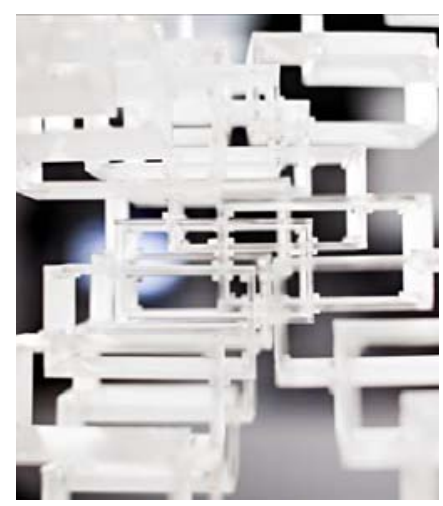

Fig. 8. The 'Micro-Mega' installation on 2014 SZlHK Bi-City Biennale of Urbanism and Architecture (right) (Photographer: Wang Hui)

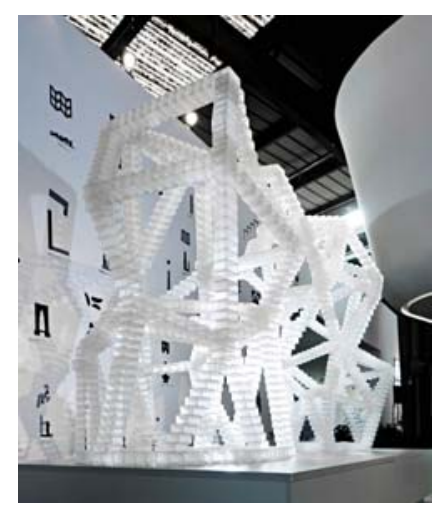

Fig. 9. The detailed joint of 'Micro-Mega' installation (left) (Photographer: Wang Hui)

\section{CONCLUSIONS}

As the architects constantly renew their design language, they are also required to look back and reflect on the organization of design methods. Professor Hanif Kara's concern should be considered as the essential foundation as 
important as the experiment in the organization of path by Frei Otto. In this vein, the integrated design methodology of architectural and structural system which aims to reconstruct the boundaries of architecture and structural engineering could be a leading trend in the future architectural design field.

\section{ACKNOWLEDGMENT}

We should like to thank the reviewers for their invaluable comments and suggestions. The paper is supported by the National Natural Science Foundation of China (Project No. 51278340).

\section{REFERENCES}

[1] Á. Moravánszky and A. Kirchengast, "In search of an Architectural Imperative, Christian Kerez and Joseph Schwartz in discussion with the publishers", Experiments: Architecture Between Sciences and the Arts. Berlin: Jovis, pp.116-136, 2011.

[2] J. Turnbull, Toyo Ito - Forces of Nature. New York: Princeton Architectural Press, pp.33-35, 2012.

[3] C. Balmond, Informal - Theories and Manifestoes of Contemporary Architecture. New York: Prestel Publishing, pp.353-354, 2002.

[4] E.F. Sekler, "Structure Construction, Tectonics", Structure in Art and in Science, New York: Brazil, pp.89-95, 1965.

[5] Y.M. Liu, Y. C. Liu, R. H. Sheng, Y. H. Ruan, Y. Lu, and J. F. Wang. "A Study on the Multi-Tower Connected Structure of Hangzhou Civic Center,” Build. Struct., vol. 1, pp. 54-58, 2009.

[6] L.X. Li, Y. Liu, and L. Liu, "The Posture of Architecture's Intervention into Nature", Time Archit. vol. 3, pp. 102-107, 2012. 